\title{
'Why mouth all the pieties?' Black and women academics' revelations about discourses of 'transformation' at an historically white South African university
}

\author{
Dina Zoe Belluigi ${ }^{1}$ (D) $\cdot$ Gladman Thondhlana $^{2}$
}

Published online: 23 March 2019

(C) The Author(s) 2019

\begin{abstract}
With inequality persistent across geopolitical contexts, 'transformation' continues to be expediently cited in the rhetoric of higher education institutions. Illuminating alike issues worldwide, the paper critically examines race, inequality and oppression among the black and women academics who were selected as recipients of post-apartheid academic development programmes at an historically white institution in South Africa. Utilising a report-and-respond approach, participants initially responded in a questionnaire to definitions of notions of transformation espoused within The Integrated Transformation Plans of South African universities. This was followed by non-deterministic small group discussions of the researchers' interpretations of those responses. The recipients' lived experiences provide deep insights, from within, into the misalignment between those discourses espoused and those practiced, which have implications for transforming the institutional culture of the dominant in-group. Emerging ahead of the implementation of a self-regulatory tool for higher education institutions across that national context, many of the participants called for structural accountability mechanisms in the face of their frustration with current ineffectual approaches. A concern about institutional responsiveness to research findings of such critical studies is raised.
\end{abstract}

Keywords Transformation · University $\cdot$ Equality $\cdot$ Race $\cdot$ South Africa $\cdot$ Academic development

\section{Introduction}

Acknowledged across disciplinary traditions, geographic and socio-economic contexts, is the challenge of achieving equality in education. Clear patterns of inequality and disadvantage, in

Dina Zoe Belluigi

d.belluigi@qub.ac.uk

1 School of Social Science, Education and Social Work, Queen's University Belfast, 69/71 University Street, Belfast BT7 1HL, Northern Ireland

2 Department of Environmental Science, Rhodes University, Grahamstown, South Africa 
terms of race, gender and class in particular (Alexander and Arday 2015; Osorio 2009), have emerged from studies analysing access, curricula and institutional culture in higher education (HE). Whilst this is perhaps to be expected in contexts with legacies of oppression, continued calls for change are prevalent in many seemingly more equitous contexts, where previously marginalised voices now have more capital post-massification. For some, this persistence is symptomatic of the fundamentally unjust nature of educational systems as products and producers of the Culture Industry established in the interests of the elite (Bourdieu 1977; Freire 1972; Ladson-Billings 1998). At an institutional level, such continuation may represent 'a form of tacit intentionality' to privilege the norms and interests of those in power (Gillborn 2005, p. 485).

In many developing contexts, long-standing patterns of power from colonialism, the Cold War and related conflicts, continue to define culture, inter-subjectivity and social formation, knowledge production and its exchange (Eten 2017). These asymmetrical power structures are 'maintained alive in the criteria for academic performance, in cultural patterns, in common sense, in the self-image of peoples, in aspirations of self, and so many other aspects of our modern experience' (Maldonado-Torres 2007, p. 243). Such acknowledgement has provided the impetus for various movements and proponents of the critical tradition in adult education to grapple with the reproduction of inequality in higher education, such as that underpinned by Critical Race Theory, Black Feminist Thought and Queer Theory. A renewed sense of urgency has recently reignited student activist groups (Barnhardt 2016) globally in their calls for radical redress, popularised through hashtag movements and events such as \#Rhodesmustfall, \#Feesmustfall, \#Blacklivesmatter, \#TodosSomosAyotzinapa, ConcernedStudent1950, \#LiabilityoftheMind and \#CanYouHearUsNow. In some instances, these were marginalised student and staff activist groups, and in others, national agendas, notably in South Africa and Argentina of the global South, and in the growth of 'critical university studies' in the USA and UK.

Imbued with political capital, discourses of transformation have come to dominate higher education policy and public rhetoric, to the extent that 'transformation' as an umbrella signifier 'absorbs rather than emits meaning' (Soudien et al. 2008, p. xx). Depending on the context, transformation for social good has recently been twinned with such concepts as diversity and inclusivity (Ahmed 2012; du Preez et al. 2016), social healing (Association of American Colleges and Universities 2017), social justice and change (O’Shea et al. 2016; Singh 2011) and decolonisation (Stein and de Andreotti 2016).

In this paper, we problematise the discourse of transformation which characterises the national rhetoric of a sector in transition - that of South African higher education. The notions of transformation espoused nationally are positioned in relation to what is experienced by the supposed beneficiaries of such transformation at the institutional level.

\section{Academic equality in South African higher education}

The influence of colonial and apartheid visions, in addition to imperial and neoliberal pressures, have been strongly felt in the so-called developing context of South Africa. The de/legitimation of certain knowledge(s) over others within the colonial academy was further burdened by the ruthless implementation of apartheid ideologies and segregation along racial lines in education at all levels (Paasche 2006). Higher education institutions were differentiated by selected 'ideological, economic and social functions in relation to the reproduction of the apartheid and capitalist social order' of inequality (Badat 2009, p. 457) This racial segregation was formalised by what has become known as historically black institutions (HBIs) and historically white institutions (HWIs). 
In the wake of colonialist and apartheid legacies, the South African state positioned public education in the service of the public good, by acting as a democratising force, responding to the global economy and challenging post-conflict legacies of oppression. As such, State discourses of transformation oscillated between political democratisation, economic reconstruction and development, and redistributive social policies aimed at equity (Department of Education 1997, p. 1.7). Beyond the scope of this paper is the debate as to whether large-scale sweeping structural changes at each of those axes is possible, in the wake of what is known as the 1994 negotiated political settlement which saw little change in economic power-sharing.

A shift from 'crisis' in development rhetoric to the post-apartheid 'rainbow nation' dream (Lebeau and Mills 2008) of a non-racial and non-sexist HE, became entangled in the discourses of 'transformation' in the sector (Badat 2011), which persists today (Venter 2015). How congruence is ascertained, between such espoused discourses and what is practiced and experienced, is an area of debate (Engelbrecht and Bhengy 2015). Strategies such as quota systems and equity policies for affirmative action were implemented for structural pathways towards achieving 'transformation' at HWI (Badat 2008). The signifier of such 'transformation' was at first taken to be demographic changes in the racial and gender profiles of students given structural access to the institution, later shifting to those who survive and thrive to succeed within its ranks, with funding formulae awarding throughput and completion rates. The challenges and successes of the sector, in relation to educational equity of the student stakeholders, is an active area of professional practice and scholarship.

The lack of change, at an institutional level, continues to be the subject of much controversy and public debate (Universities South Africa 2015). This paper looks at what is recognised as 'the most glaring collective failure' (Transformation Strategy Group and Transformation Management Group 2015, p. 11) and 'poor picture' of institutional transformation, painted by national demographics of the academic staff (Govinder et al. 2013, p. 5). In 2014, two decades after apartheid ended, whites made up more than half $(53.2 \%)$ of the academic staff against a national demographic of $79.2 \%$ black South Africans (Department of Higher Education and Training 2015). ${ }^{1}$ When disaggregated, HWIs continue to be overwhelming white, and in the natural sciences, male. Explicit national discourses about the 'urgent need to radically change the demographics of our professoriate' (Nzimande in Jansen 2015), is the assumption that the access of black and/or women ${ }^{2}$ academics will equate to 'deracialisation and degendering of the academic workforce' (Transformation Strategy Group and Transformation Management Group 2015, p. 12).

As a seeming panacea for academic equality, various 'development' programmes were piloted from the early 2000's in a number of HWI, including the institution from which the participants of this study were drawn. The models for these programmes were imported and funded by philanthropic organisations in the global north, tracing geopolitical ties with countries of democratic, capitalist leanings. The recipients of these programmes were positioned in nationalist discourses as contributing

\footnotetext{
${ }^{1}$ Such racial categorisation is standard in the national equity discourses (RSA 1998). The racial distinctions include 'white' to distinguish those of Caucasian descent; 'black' for those of black African descent; 'Indian' for those of descendants of those known elsewhere as western Asian; 'coloured' is inclusive of those of 'mixed race' or KhoiSan descent.

${ }^{2}$ Ethical approval for the study was awarded by an institutional committee, with ethical conduct followed at every step. To reduce the considerable risk for participant involvement, identifiers of the case study institution, specific programme titles, and the names of participants of this study have been excluded from dissemination.
} 
to the intellectual and academic decolonisation, de-racialisation and de-gendering of the inherited intellectual spaces of South Africa's universities, and more generally, to reorienting universities to serve, in accordance with their social purposes, new constitutional, economic and social needs and development challenges (Higher Education of South Africa 2011, p. 11).

Generally small-scale and measured, the programmes incrementally altered institutional demographics in stable ways, permitting access to a select few 'talented' individual academics, while not relinquishing existing constructions of quality. Approaches to 'access for success' from student educational development were translated to equity initiatives for similarly located 'previously disadvantaged' staff (Belluigi and Thondhlana 2019). In contrast to the brief orientation for mainstream newly appointed academics, recipients of these programmes were apprenticed through an intensive routine of mentorship and evaluation aligned with performance management in research, teaching and community engagement prior to their selection for probation towards tenure and more secure employment. What was not acknowledged, in that post-conflict context where power had not shifted from the white intellectual elite, is that such professional socialisation models emphasise 'worker adaptation to the work environment [where] reproduction of organizational norms engenders the most rewards' (Sulé 2014, pp. 432-433).

In the 18 years of their piloting and implementation, these programmes have adopted various titles, reflective of their funders, political rhetoric and aims. Evaluated extensively for their efficacy in ensuring successful outcomes, elements of these initial models have been retained in the three nationally funded, centralised programmes of the Staffing South Africa's Universities Framework (SSAUF): the 'New Generation of Academics Programme' (nGAP), 'Existing Academics Capacity Enhancement Programme', and 'Higher Education Leadership \& Management Programme' for black nationals and, where underrepresented, women. This paper explores notions of transformation from the perspectives of the recipients of the initial programmes, and who were tasked, to varying degrees, with embodying or effecting transformation at an historically white institution.

\section{Methodological approach}

Studies of affirmative action internationally have been found to most often focus on the reception of the in-group who are experiencing change and/or their underpinning ideologies, rather than the recipients (Kravitz et al. 1997). We would argue that the recipients of such programmes are valid sources, as they have an emigre consciousness (Said 1993) in their liminal positioning. Situated neither as insiders nor outsiders, powerful nor powerless, their lived experiences make visible taken-for-granted mechanisms of reproduction within educational systems. While there are costs and consequences to personal negotiations of the politics of belonging, such a position of alterity enables 'call[ing] into question the rules of functioning' (Ladson-Billings 1998, p. 22). In acknowledging this, we follow humbly in the footsteps of those of the critical traditions of research in higher education who hold that 'we must allow those who are socially-marginalized to determine what is critical' (Berry 2017, p. 63).

This study has been informed by this ethos, from its very inception. We were encouraged by a group of programme recipients to undertake a study exploring their differing receptions of group membership and transformation, following a presentation of our findings of a study on 
societal asymmetries in terms of race and gender on students' peer-assessment dynamics in a South African university (Thondhlana and Belluigi 2016). The historically white institution, within which these participants were situated, had been progressive in piloting various iterations of such developmental programmes from 2000. Of the 53 recipients in the period of 2000-2017, 27 responded to our invitation to participate; 13 were not contactable, 3 declined and 10 were excluded as they were newly appointed. The data generation process was structured by a report-and-respond approach (Stronach and Piper 2004) which utilised mixed-methods: questionnaires followed by small group discussions. The questionnaire was divided into sections about transformation, access, evaluation and identity. Twenty-one of the participants chose to respond to the questions about transformation, from which this paper is drawn. To narrow down the many possible themes and meanings associated with the term transformation, we utilised the 9 notions identified in the comprehensive review of the Integrated Transformation Plans (ITPs) of South African universities conducted by the national Transformation Strategy Group and Transformation Management Group (2015). Citing the exact definition, participants were asked to indicate whether each notion was 'espoused', 'experienced in practice'; 'both', or 'not practiced', and then to add qualitative data by reflecting on 'what you think the significance is of these notions for your own experiences and those of others involved in transformation programmes and structures in X [HEI]'. We presented our interpretations of these responses at three small group discussions to invite further critique, insights and comment, which have informed our representations in this paper, which itself has been circulated to participants. Numerical values and excerpts from their responses are included within the paper, with a code assigned to each respondent (preceded by a hashtag).

Adding to the diverse epistemological, disciplinary, national and personal backgrounds of the participants, one of the authors had been a programme recipient and the other worked within educational development. The participatory process involved blundering across the 'threshold of educational darkness' where one 'engages with issues... not to solve them or necessarily to grasp them, but to endure them and stay with them' (Bengtsen and Barnett 2016, p. 16). During the research process, we experienced varying degrees of existential and ethical crisis about our own positionality (as noted by fellow researchers Jawitz 2012; Walker 2005), and under the weight of the emotional burden of initiating a participatory study when we could not responsibly make promises about its use-value for altering the institutional conditions which participants experienced. A component of this is echoed in the critique by the US scholar Gloria Ladson-Billings (1998, p. 22) that radical theories where 'ideas are laudable but the practice leaves much to be desired' can only be indulged by those with 'the luxury... to ruminate' in such research. As we revisit in the 'Discussion: the significance of such misalignment on recipient experiences' section of this paper, a number of the participants voiced their fatigue and disillusionment with institutional research on transformation, which was experienced as a mechanism utilised by those in power to defer change. In an attempt to increase the impact of our findings, briefing papers have been circulated at committee level within the institution, and are being used to formulate a larger international research network. Sharing this study through publication contributes to the larger calls for nuanced considerations of transformation, with its findings emerging ahead of the national Transformation Barometer Framework in 2018. The findings relate to the areas 'diversity and inclusivity' and 'social inclusion/exclusion/cohesion' which have been identified as pressing to inform policy implementation by the national oversight committees (Transformation Strategy Group and Transformation Management Group 2015, pp. 15-16). Whilst limited, such critical studies in 
higher education transformation take their impetus from the impossible hope that 'transformation and justice is possible if we continue the work to name, resist, and challenge everyday' (Huber and Solorzano 2015, p. 314) macro- and micro-aggression and oppression.

\section{Analysis: participants' responses to the notions of transformation}

Common to many other national contexts, discourses of transformation have been abused in relation to equity in educational settings (Archer 2007; Pilkington 2018). The critical discourse approach we utilised acknowledges that representation does not preclude 'strategic presentation as much as belief and conviction: playing the game as much as striving for self-hood' (Mitchell 1996, p. 152). Positioning our participants' lived experience as having primacy over the authority of the intentionality of the institution's espoused discourses, the study is characterised by an intertextual approach to enable rich insights into how these key insiders re/negotiated the social practices of that particular institutional culture.

Enabling transgression of researcher/respondent roles, we invited participants to analyse the validity of the notions of transformation utilised as the initial 'text' for discussion. These notions of transformation had been identified through an analysis of meaning-making themes within The Integrated Transformational Plans of the country's public universities (Transformation Strategy Group and Transformation Management Group 2015). They were labelled as 'reparation', 'compliance', 'relevance', 'evolution', 'psychological', 'contexts', 'social', 'review' and 'mission'. On the whole, participants found them helpful to tease out what was espoused compared to what was practiced and experienced, with one participant stating that 'these notions neatly separate different perspectives on transformation' (\#4). More critical commentary was that they 'hide the reality' of the politics of transformation and its relation to a specific historical legacy of 'racism and discrimination as an institution and as a country' (\#6).

As indicated in Fig. 1, the notions of the transformation which participants perceived as the most dominantly espoused in the HWI were reparation (21/21), context (18/21), social (18/21), mission (17/21), relevance (16/21), evolution (16/21) and psychological (15/21). These were not aligned with what was experienced as the dominantly practiced notions of transformation, compliance (18/21) and review (15/21).

The analysis which follows is structured by those notions which participants indicated were most prevalently espoused within institutional discourses, followed by those most dominant in practice.

The most dominantly espoused institutional discourse - that of reparation - has been one of the most controversial notions in South African politics and in contexts such as the US since Moore (1963). In the Integrated Transformation Plans, this notion was constructed as

a process of making amendments. It is about bringing about radical changes in ourselves and advocating change to structural defects and dehumanising systems for the betterment of higher education whereby it is possible to build a culture of mutual respect, trust, co-operation, tolerance and humaneness (Transformation Strategy Group and Transformation Management Group 2015, p. 5).

While all 21 respondents marked this as an espoused discourse, only 6 experienced it as aligned with practice. Fifteen respondents indicated they had not experienced this notion in practice. Analysis of the qualitative responses indicated that this variation was reflective of benevolent references to this discourse at agential level as 'compassionate' (\#19). 

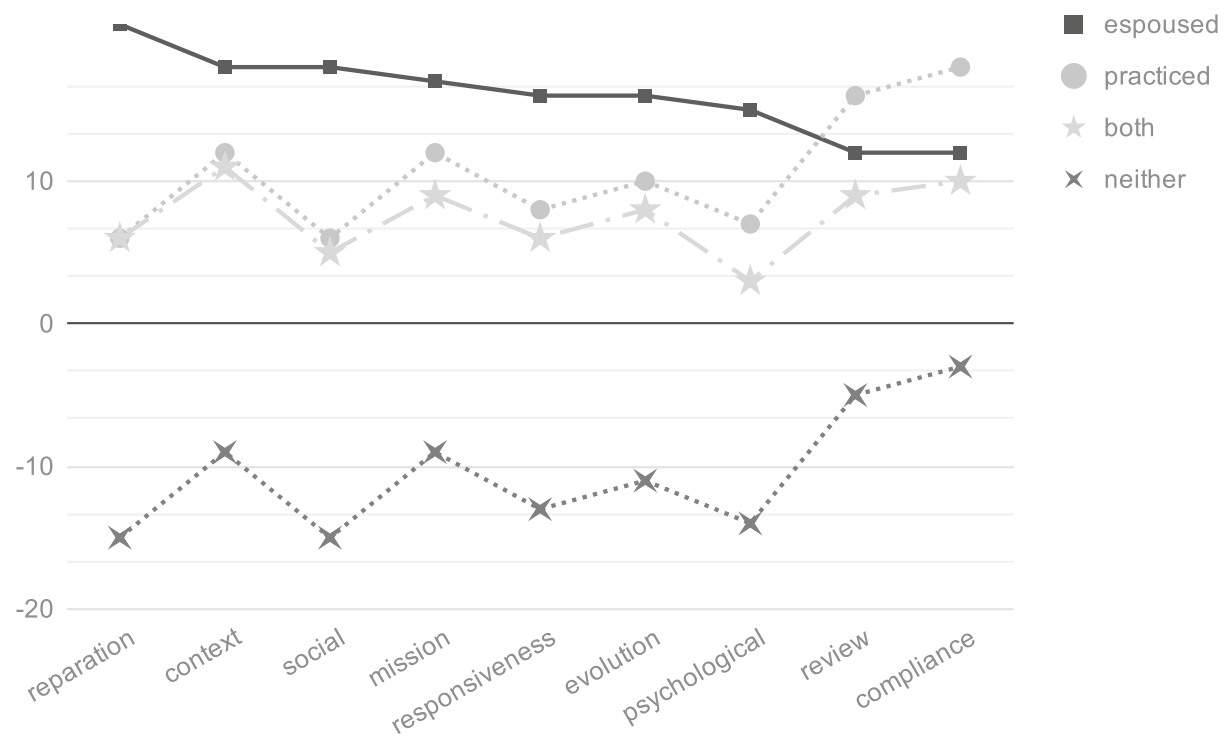

Fig. 1 A mapping of participants' reception of transformation discourses

[C]hange that is considered to be "radical" from the perspective of the advantaged party is the only real change that is considered at X; and so the reparation is espoused, but meaningless (\#4).

The institutional focus on the numerical diversity was seen as an avoidance of reckoning with structural, cultural or material reparation.

The second most dominantly espoused notion of transformation (18/21), according to participants' experiences, was that of context, defined as providing

opportunities for an excellent teaching and learning experience that is contextually responsive to the challenges of globalisation and of a society in transition (Transformation Strategy Group and Transformation Management Group 2015, p. 5).

This had the highest indication of alignment between the espoused theory and the theory-inuse (11/21), possibly because programme recipients had direct experience of formal qualifications in teaching-and-learning as part of their professional development.

Of concern for critical democratisation processes is the 'cooperation of each of the various components of a diverse society' (Darder 2012, p. 425). Social transformation was defined in the Integrated Transformation plans as

a change that takes place between individuals and where historical power relations are fundamentally altered and equalised (Transformation Strategy Group and Transformation Management Group 2015, p. 6).

While 18 participants indicated this was espoused within the institution, only a third (6) experienced it as aligned with practice. Moreover, 15 participants indicated such transformation was not practiced. Participants' qualitative responses provided insight into the large gap between this dominantly espoused discourse and what was practiced. They questioned the interests served by the strong assimilationist ethos of the hierarchical academic environment, 
where mentorship "move[s] the previously-disadvantaged party into the system of the advantaged party more efficiently — which automatically places the existing system of power relations in a superior position' (\#4). Many felt that agential will was not prevalent, and since the 'systems are only as strong as the people who make them... if people don't want to change, the [systems] will not' (\#25).

Transformation as mission was constructed as 'fundamental and purposeful advancement towards specified goals - individual, collective, cultural and institutional' (Transformation Strategy Group and Transformation Management Group 2015, p. 6). Influenced by trends in global management structures, the institution had over a 10 -year period concertedly aligned its vision and mission statement with national imperatives for transformation. Seventeen participants indicated it was espoused; 12 indicated it was experienced as a theory-in-use, of which 9 experienced it as both. This was one of two notions of transformation which all participants agreed were within the institution (the other was 'reparation').

The notion of relevance was defined as

a process of becoming useful in and to society at large. It is a multifaceted and integrated process by which the university continuously renews itself in an ongoing effort to complement national development and societal goals (Transformation Strategy Group and Transformation Management Group 2015, p. 5).

The 16 participants, who indicated this was espoused, were divided between those who had experienced it as a practiced notion and those who had not, possibly indicating variation in departmental cultures. The central placement and reward of education development and community engagement initiatives within institutional tenure and promotion assessment criteria, had contributed to practical implementation of responsiveness to local concern. However, many participants felt that such initiatives were marginal, with 15 respondents indicating they had not experienced 'relevance' in practice, and 3 experienced it neither espoused nor practiced.

Enlightenment notions of progress underpinned the collegial rationality (Luckett 2006) model of evaluation at the institution more generally. In our analysis, we found that those few participants who were generally most positive about how institutional change was happening, were those informed by an understanding of transformation as an inevitable, ongoing progress. This interpretation was confirmed at the small group discussions. However, Critical Race Theorists argue that racism, in particular, requires sweeping and radical change (Crenshaw 1988; Ladson-Billings 1998). The notion of transformation as evolution attempts to encompass both aspects, as

An inevitable (involuntary) process of change. It is an ongoing process and not an event or an end in itself. It is a journey that requires courage, tolerance, fairness, and equity and the willingness and courage to ask the difficult questions (Transformation Strategy Group and Transformation Management Group 2015, p. 5).

Sixteen participants experienced evolution as espoused, 10 as practiced and 8 as both espoused and practiced. Many of the respondents articulated their disillusionment with the HWI's 'reluctant' (\#25) acceptance of such eventuality, and the passivity in relation to the establishing the conditions suggested in second aspect of the definition noted above.

Most of these respondents pointed to a 'neglect' of the psychosocial dimensions of transformation 'as an effect resulting from untransformed attitudes' (\#8). Superficial diversity had created a numbers game culture with 'no recognition of the value of a person' (\#25). The notion that relates to agential change most directly (in addition to social, discussed above) is 
the notion of transformation as a psychological 'change process that takes place in people. It involves the promotion of moral, ethical and social values as well as the enhancement of moral regeneration' (Transformation Strategy Group and Transformation Management Group 2015, pp. 5-6). Because of their own positioning as change agents in the national discourses, this notion struck a chord with most participants.

Transformation of society starts with the individual. It is a difficult and often daunting process, as the individual tries to understand what she is meant to change from. Further, when the individual is placed in an environment where transformation is an objective, and she is targeted as part of that process at the institution, the question about what is being transformed is further complicated (\#17).

Fifteen participants indicated psychological transformation was espoused within the institution, with the least alignment in what was espoused and practiced. A small minority of participants (3) used a conciliatory tone about the institution in their responses, noting that when the institution did create spaces, individuals did not assume responsibility for realising dialogue. The majority of participants were critical of those individuals with power and influence, who were experienced as the least willing to engage with this notion of transformation.

I wish there was a switch where you could turn people into decent human beings. They have the capacity to empathise, but why in their roles are they not? (\#25).

The neglect of this notion of transformation was seen to create the conditions for reproducing systems of oppression.

The least foregrounded in the espoused discourses, were those two notions most dominantly experienced in practice - compliance and review. That most dominantly experienced (18/ 21) was compliance, defined as 'transformation as a response to constitutional and legal requirements' (Transformation Strategy Group and Transformation Management Group 2015, p. 6). Through various external legislative methods, most recently The Policy Framework for the Realisation of Social Inclusion in The Post-School Education and Training System (DHET 2016), the Department of Higher Education and Training aimed to ensure that HEIs

have in place anti-racism and anti-discrimination policies as well as grounding programmes that focus on building an inclusive society (Transformation Strategy Group and Transformation Management Group 2015, p. 5).

While a key ethos of such legislative frameworks is social cohesion and inclusion, participants felt that such transformation within the institution was applied 'only when convenient' (\#25) 'as an obligation, an externally located drive for change according to national prerogatives' rather than 'a collective academic struggle for self-reconstruction at the everyday level of departmental cultures’ (\#16).

Because of this, much of the transformation objectives put in place become mere 'window-dressing' and do not result in actual change or real transformation that benefits those who lack systemic and institutional power (\#14). 
Within both the questionnaire and the small group discussions, participants expressed their distaste for this 'forced necessity' (\#18). The consequences of legislation which socially locate the individual, engendered limitations for radical structural and cultural change.

I am looking forward to a time when Black people aren't so treated as DESIGNATED, BUT they are seen as scholars in their own right and who do not require to be designated into certain groups. I am also looking for a time when everyone who sits in selection committees become acutely aware of the racial past which has perpetually disadvantaged certain people...If this becomes the case, we will employ the previously disadvantaged without the need for the whip of the law to force us into line (\#6).

Transformation as a review process of 'evaluating existing conditions' (Transformation Strategy Group and Transformation Management Group 2015, p. 6) was the dominant theory-in-use within this HWI (16/21). This was one of the notions of transformation that indicated the smallest gap between those who indicated it was espoused and those who indicated alignment in practice with the theory-in-use. At the time of the data generation, institution-wide curriculum review in response to students' calls to 'decolonise the curriculum' was in the planning phase at the faculty level. Despite this prevalence, a small number of participants experienced a 'conscious resistance to change' from those in positions of power at departmental level, which one articulated as 'no review. Just a lot of status quo. No rocking the boat allowed! And if you rock, CONSEQUENCES' (\#25).

Of the notions outlined above, those which the majority of participants experienced as not practiced were reparation (15/21), social (15/21) and psychological (14/21).

\section{Exploring the gaps}

In this section, we explore participants' perceived reasons for the gaps identified above, in addition to the implications for their individual agency within that institutional culture.

These gaps were seen as a symptom of the misalignment between the intentionality of aspirational national and strategic institutional transformation discourses, pitted against the theory-in-use of the majority of dominant members at this historically white institution whose identities remained rooted in inherited legacies of privilege, discrimination and inequality.

I would say that the bigger issue is the institution and the staff at it who are stuck in their old ways. And have not been forced to come to terms with the fact that they cannot pretend not to be racist, sexist, patriarchal individuals and carry on with life... if you raise it and call people on it, you pay for it. So this institution is a safe haven for the same-old same-old. Any attempts to change it label you a troublemaker, and for this there are consequences. Safe spaces do not exist (\#25).

This echoes common explanations on a national level that 'the pace, nature and outcomes of institutional change' are impacted by the 'different social agents and actors acting in cooperation and/or conflict within higher education and its institutions' (Badat 2009, p. 456). The locatedness and positionality of certain structures and individuals impact on institutions' responsiveness to change. In our discussions, participants spoke about how in that postconflict context, 'progress that is made without reconciling' intergenerational notions of transformation 'is limited, fragmented, and almost coincidental' (\#4). 
Participants acknowledged the difficulties of the scale and scope of transformation within HEIs in the country generally. The narratives of three participants, who were generally positive about transformation at that HWI, were accommodating of conservative and incremental change as evolution. This commonly held view (Breetzke and Hedding 2016) has been critiqued at a national level when used to defer institutional change.

If we accept that 'transformation' is a process, and not an absolute datum or historical point, we must also insist this assertion is not used as an excuse for shifting its imperatives to an indeterminate timeless future (Transformation Strategy Group and Transformation Management Group 2015, p. 4).

Many participants accused the institution of 'being reactive to the transformation agenda' (\#8) rather than proactive. A large-scale report on such programmes within the country, similarly highlighted 'the complexities of [their] implementation' when 'the importance of moving beyond instrumental approaches' is not foregrounded (Badsha and Wickham 2013, p. vi). As with these participants, the authors of that report pointed to the role of 'critical leadership' in

navigating competing demands, in giving focused attention to the value of representivity, and in ensuring substantive engagement from the whole university community in the development of new discourses (ibid).

Shifting political power and the will of key agents within the institution, towards a shared understanding of transformation, emerged as ways forward by the majority of participants.

The University needs gatekeepers, but it also needs people who will thoughtfully challenge gatekeepers - especially when they lose sight of the real goals. Is transformation possible if the gatekeepers are not transformed? No. The agenda of every stratum of authority must include a deep transformation that is ongoing and responsive (\#5).

The major bottleneck was identified as those in power who perceived a tension between the goals of equality and quality. They were seen as beneficiaries of what was in their self-interest to keep unaltered.

With parallels to the continued international concern with institutional culture (Tate and Bagguley 2017), emerging from participants' narratives was a characterisation of an institutional culture which strongly replicated its inherited exclusionary homogeneous past, and which positioned those who did not conform to the dominant norm as 'other'.

There is a clear reluctance to shift the way 'we' do things. The elephant in our room is a $\mathrm{X}$ one [colour associated with brand of institution], that sits and talks about how this is the way 'we' have always done things (\#25).

The dominant institutional approach adopted to change in this regard was to emphasise inclusiveness and belonging. When coupled with membership within the programmes, this produced a strongly assimilationist ethos. Such a preference for assimilation ideology has emerged elsewhere when those in positions of power determine the approach to equality (Ryan et al. 2007; Verkuyten 2006). Emphasising common-group identity may be effective for promoting intergroup harmony (Gaertner and Dovido 2012). However, there are powerful indications that in contexts where power is skewed, particularly post-conflict contexts, 
emphasising common identity may actually reduce the sensitivity of in-group members to discrimination, creating the conditions which replicate the culture of the dominant in-group (Banfield and Dovidio 2013). This phenomenon has been used to explain the 'principleimplementation gap' (Dixon et al. 2007) between attitudes espoused in principle which are not implemented in the practices of the dominant group.

Participants recognised that espoused discourses were strategically articulated to create the illusion of compliance for external stakeholders. The characterisation of an unjust system supported by prejudicial agents, with risks and costs engendered when such fundamentally unjust orientations were challenged, emerged from the participants' qualitative responses in the questionnaires and was confirmed in the small group discussions. As researchers we became increasingly aware that some, though not all, of the participants felt themselves positioned in the midst of 'competing visions regarding whose interests the university might serve, what role knowledge plays in furthering both excellence and equity, and how higher education defines and defends its own role in relation to its often stated, though hardly operational, allegiance to egalitarian and democratic impulses' (Giroux 2009, p. 12). Whilst arguably all staff and students are positioned as such, for some of these individuals such tensions bore down on them as an unacknowledged and at times unbearable weight, constraining their agency to affect change.

\section{Discussion: the significance of such misalignment on recipient experiences}

The complications of institutional culture, in addition to the agency of powerful members of in-groups in academia, render facile simplistic assertions we may make in light of this study, in terms of recommendations for policy, practice and research in this transitioning context. Rather we hope this study serves to problematise the plethora of notions of transformation which characterise espoused discourses of this sector.

Recipients of such accelerated academic development programmes are positioned 'on a tightrope' (\#7) between fundamentally different orientations to transformation. What held a strong moral obligation for these individuals were the more radical national aspirational discourses, echoed in the expectations of the growing student and activist movements. This was in contrast to the constraining authority of the strategic functionalism of the conservative institution's orientation in-use. Underpinning the tensions of such expectations of transformation, are the irresolvable paradoxes of radical social change. These are evident too in the uncertain, often seemingly contradictory, directions of the intertextual reflections of the participants we have outlined above. Participants were painfully aware of the limited impact of external coercive approaches, and wary about claims that changes in the demographics of power would address inter/personal dynamics, or have a significant effect on the altering the current delegitimation of heterogeneous social and knowledge formations of the 'western' academy. The articulated desire for transformation as internal, agentic or qualitative change within the dominant in-group, which emerges from their responses; is pitted against calls for institutional responsibility and external accountability. This emphasis on structural imposition had been borne from their experiential knowledge that such shifts were improbable and insufficient for this context.

Careful consideration of the policy-implementation gaps within this context would be necessary to make sure that the models being adopted were not counter-productive. For instance, one of the consequences of assimilation approaches, which adhere to commongroup identity, is that they do not 'arouse motivation' nor solidarity in majority-group members 'to initiate protests against the injustice that underpins potential intergroup conflict' 
(Banfield and Dovidio 2013, p. 840). The implementation of minimum quota targets has the project of transformation 'meander[ing] away from any substantive change, particularly in the individual' (\#1). In such ways, the conditions for transformation of the majority white staff and for cultivating awareness for their responsibility in altering the institutional culture were mitigated against.

As the participants of our study are those bestowed with hope, aspiration and a degree of individual agency to influence higher education in the future, their experiences have considerable importance for realising equality in the South African academy. The retention of black academics is a recognised problem in the sector. Common across participants' narratives was the disheartening impact of the misalignment of discourses with practices, on their initial commitment to equality. Becoming conscious of the ugly realities of the institution resulted in disillusionment in an institutional culture which did not

accept the necessity of reparations or restructurings, so why mouth all the pieties? Initially, it feels as though it's a start, and one feels bad about complaining when others seem to be trying. But after many months of it, you realize that it's really the whole deal, and there's nothing more. That's a disturbing realization (\#4).

The vast majority of the participants articulated feeling their agency frustrated by institutional, cultural and individual resistance to substantive transformation. This was particularly the case with those who self-identified with an obligation to effect transformation, who had become increasingly exasperated by how their agency was most often thwarted, rather than supported or extended, by larger institutional approaches. Being at the 'rockface' (\#25) between the politics of representation and the politics of belonging was for many untenable and unsustainable.

I have to admit to severe fatigue and a feeling of being constantly under scrutiny and seeing no results. This ends up being invisible, unacknowledged and strenuous labour that I am no longer willing to do for a university that has shown great disregard for people of my socio-political demographics and positionalities (\#21).

This phenomenon of 'battle fatigue' is acknowledged in studies of minority experiences in higher education (Smith et al. 2016; Wozolek 2015; Bhopal et al. 2018) where research participants who are traumatised by their marginalisation exhibit 'resistant or disengaging behaviour [as] a defensive mechanism that shields them from their lived realities' (Alemán and Gaytán 2017, p. 142). The constant scrutiny of such programmes differs from that characterising minority experiences in other contexts, such as the studies in the UK which have noticed that such academics' 'silenced state is a burdensome cycle that is rarely broken' (Stanley 2006, p. 701). Monitoring and evaluation of the programmes themselves, in addition to constant assessment in reference to performance indicators of 'development', created an audit culture of surveillance and visibility which participants recognised was at odds with the lack of accountability for institutional transformation, and for the transformation of their mainstream colleagues. Where the theme of silencing most damningly emerged in this study, was in the containment of challenging findings. This is an indictment of the relationship between research-policy-implementation-practice in higher education institutions (HEIs). It points to the ineffectualness of programme evaluations to inform systemic and cultural change, and to the importance of critical studies in higher education transformation. 


\section{Conclusion}

This study contributes to those exploring the significance of discourses and mechanisms of power on equality in higher education. By providing a channel to voice the lived experiences of those positioned as 'diverse', this study provides global readership insights from academics of the costs, problematics, and politics of inclusion within institutions with explicit legacies of exclusion.

Cutting across the notions of transformation prevalent in South African HEIs is 'the development of an inclusive narrative of progress and equality in mind' (Transformation Strategy Group and Transformation Management Group 2015, p. 5). In South African higher education, the slow growth of access for people-ofcolour is often utilised as an indicator of transformation. This study's findings, of the prevalence of transformation as 'compliance' and 'review' in the practices experienced by black and/or women academics at this historically white institution, is therefore not surprising. What is disconcerting is that the impetus for social change of the espoused notions of transformation as 'reparation', 'relevance', 'context', 'psychological' and 'social' had less traction in practice, resulting in what participants viewed as an impoverishing of transformation into superficial numerical diversity. Turning such representational power on its head, we positioning the validity of the lived experiences of programme recipients as of primary importance when analysing the ways in which transformation discourses prevalent in higher education have been effected.

Emerging across this paper are the many tensions between structure versus agency, coercion versus consent, which perhaps unsurprisingly characterise the negotiations of social change within this macrocosm of authority resisting transition. Participants of this study suggest that policies and practices underpinned by conflict theory may be more conducive for creating the conditions to catalyse transformation in contexts of dramatic inequality and oppression. They do so because of their experiential awareness that promotional discourses of inclusion and diversity do not acknowledge that the ideals, of qualitative self-criticism and transformation, are being resisted by the current beneficiaries who rarely act against their own self-interest. Participants indicated frustration with the dominant institutional culture of this historically white university, as its common-identity approaches continued to dull consciousness of injustice.

The Transformation Barometer Framework, which was set to take place across that South Africa's public higher education institutions in 2018, is a formidable national intervention which provides breadth and depth regarding the various areas of analysis required to inform and evaluate transformation policy and implementation. However, it is yet to be seen whether such a 'self-regulating tool' (Transformation Strategy Group 2017) will grow teeth in institutions, such as this case study, without external accountability. Further mechanisms and avenues to hold institutions to account for their espoused discourses may be required. We would argue that those, with a genuine desire to meaningfully transform the higher education landscape, should look to the perceptions and experiences of those previously excluded as critical stakeholders of transformation in this sector. South African higher education, riddled with legacies of prejudice, hierarchy and systemic inequality, provides an example of the urgent necessity to engage critically with the ambiguities of negotiating change within the academy. 
Open Access This article is distributed under the terms of the Creative Commons Attribution 4.0 International License (http://creativecommons.org/licenses/by/4.0/), which permits unrestricted use, distribution, and reproduction in any medium, provided you give appropriate credit to the original author(s) and the source, provide a link to the Creative Commons license, and indicate if changes were made.

\section{References}

Ahmed, S. (2012). On being included. Durham: Duke University Press.

Alemán, S. M., \& Gaytán, S. (2017). 'It doesn't speak to me': Understanding student of color resistance to critical race pedagogy. International Journal of Qualitative Studies in Education, 30(2), 128-146.

Alexander, C., \& Arday, J. (2015). Aiming higher race, inequality and diversity in the academy (p. 50). London: Runnymede http://www.runnymedetrust.org/uploads/Aiming Higher.pdf. Accessed 15 Oct 2017.

Archer, L. (2007). Diversity, equality and higher education: A critical reflection on the ab/uses of equity discourse within widening participation. Teaching in Higher Education, 12(5-6), 635-653.

Association of American Colleges \& Universities. (2017). Truth, Racial Healing \& Transformation (TRHT) Campus Centers. Association of American Colleges \& Universities. Text. http://www.aacu.org/newmansown-wkkf. Accessed 22 Aug 2017.

Badat, S. (2008). Redressing the colonial/apartheid legacy: Social equity, redress and higher education admissions in democratic South Africa. Presented at the conference on affirmative action in higher education in India, the United States and South Africa, New Dehli. https://core.ac.uk/download/pdf/49241217.pdf. Accessed 19 Aug 2011.

Badat, S. (2009). Theorising institutional change: Post-1994 South African higher education. Studies in Higher Education, 34(4), 455-467.

Badat, S. (2011). Scholarship in a context of Transformation. Paper presented at the Centre for Higher Education Research, Learning and Teaching Academic Orientation Programme, Rhodes University Grahamstown.

Badsha, N., \& Wickham, S. (2013). Review of initiatives in equity and transformation in three universities in South Africa. Wynberg: Cape Higher Education Consortium.

Banfield, J. C., \& Dovidio, J. F. (2013). Whites' perceptions of discrimination against Blacks: The influence of common identity. Journal of Experimental Social Psychology, 49(5), 833-841.

Barnhardt, C. (2016). Embracing student activism. Higher Education Today. https://www.higheredtoday. org/2016/03/02/embracing-student-activism/. Accessed 29 May 2017.

Belluigi, D. Z., \& Thondhlana, G. (2019). Transformation or 'training the dog'? Faculty insights into approaches to access within an historically white university in South Africa. Equity \& Excellence in Higher Education.

Bengtsen, S., \& Barnett, R. (2016). Confronting the dark side of higher education. Journal of Philosophy of Education n/a-n/a.

Berry, T. R. (2017). The intersections of Africana studies and curriculum theory: A counter-Western narrative for social justice. Journal of Curriculum Theorizing, 32(1) http://journal.jctonline.org/index. $\mathrm{php/jct/article/view/462.} \mathrm{Accessed} 14$ July 2017.

Bhopal, K., Brown, H., \& Jackson, J. (2018). Should I stay or should I go? BME academics and the decision to leave UK higher education. In J. Arday \& H. S. Mirza (Eds.), Dismantling race in higher education. racism, whiteness and decolonising the academy (pp. 125-139). Basingstoke: Palgrave Macmillan.

Bourdieu, P. (1977). Reproduction in education, society and culture. Newbury Park, Calif: Sage.

Breetzke, G. D., \& Hedding, D. W. (2016). The changing racial profile of academic staff at South African higher education institutions (HEIs), 2005-2013. Africa Education Review, 13(2), 147-164.

Crenshaw, K. W. (1988). Race, reform, and retrenchment: Transformation and legitimation in antidiscrimination law. Harvard Law Review, 101(7), 1331-1387.

Darder, A. (2012). Neoliberalism in the academic borderlands: An on-going struggle for equality and human rights. Educational Studies, 48(5), 412-426.

Department of Education. (1997). Curriculum 2005: Specific outcomes, assessment criteria, range statements, Grade 1-9.

Department of Higher Education and Training. (2015). Staffing South Africa's universities framework (pp. 1-30). Pretoria: Department of Higher Education and Training http://www.justice.gov. za/commissions/FeesHET/docs/2015-Staffing-SAUniversitiesFramework.pdf. Accessed 26 Jun 2016.

DHET (Department of Higher Education and Training). (2016). Policy framework for the realisation of social inclusion in the post-school education and training system. Government Gazette no 40496. Cape Town. Available at http://www.dhet.gov.za/SiteAssets/Latest\%20News/2017/January/Gazetted-Policy-Frameworkfor-the-Realisation-of-Social-Inclusion-in-PSET-No40496-Notice-no-1560.pdf. Accessed 13 Mar 2019.

Dixon, J., Durrheim, K., \& Tredoux, C. (2007). Intergroup contact and attitudes toward the principle and practice of racial equality. Psychological Science, 18(10), 867-872. 
du Preez, P., Simmonds, S., \& Verhoef, A. H. (2016). Rethinking and researching transformation in higher education: A meta-study of South African trends. Transformation in Higher Education, 1(1), 7.

Engelbrecht, M., \& Bhengy, N. (2015). Planning for transformation in South African higher education (pp. 112). Presented at the EAIR 37 th Annual F orum, Krems, Austria. http://eairaww.websites.xs4all. nl/forum/krems/PDF/1683.pdf. Accessed 1 June 2017.

Eten, S. (2017). The role of development education in highlighting the realities and challenging the myths of migration from the global south to the global north. Development Education Review, 24, 47-69.

Freire, P. V. (1972). Pedagogy of the oppressed. Herder and Herder.

Gaertner, S. L., \& Dovido, J. F. (2012). Reducing intergroup bias: The common ingroup identity model. In P. A. M. Van Lange, A. W. Kruglanski, \& E. T. Higgins (Eds.), Handbook of theories of social psychology (pp. 439-457). Thousand Oaks: Sage.

Gillborn, D. (2005). Education policy as an act of white supremacy: Whiteness, critical race theory and education reform. Journal of Education Policy, 20(4), 485-505.

Giroux, H. A. (2009). Academic labour under siege: Towards a politically engaged professionalism. Advocate, 20(2), 10-13.

Govinder, K. S., Zondo, N. P., \& Makgoba, M. W. (2013). A new look at demographic transformation for universities in South Africa. South African Journal of Science, 109(11/12), 11.

Higher Education of South Africa. (2011). A generation of growth. Proposal for a National Programme to Develop the Next Generation of Academics for South African Higher Education. Pretoria: Higher Education of South Africa. http://www.usaf.ac.za/wp-content/uploads/2017/03/12430-HESA-Next-Generation-V4.pdf. Accessed 9 Jan 2012.

Huber, L. P., \& Solorzano, D. G. (2015). Racial microaggressions as a tool for critical race research. Race Ethnicity and Education, 18(3), 297-320.

Jansen, L. (2015). Varsities set to transform faster. The Mercury. http://www.pressreader.com/south-africa/themercury/20150514/281539404532722. Accessed 31 May 2017.

Jawitz, J. (2012). Race and assessment practice in South Africa: Understanding black academic experience. Race Ethnicity and Education, 15(4), 545-559.

Kravitz, D. A., Harrison, D. A., Turner, M. E., Levine, E. L., Chaves, W., Brannick, M. T., et al. (1997). Affirmative action: A review of psychological and behavioral research. https://works.bepress.com/maureen conard/8/. Accessed 1 March 2017.

Ladson-Billings, G. (1998). Just what is critical race theory and what's it doing in a nice field like education? International Journal of Qualitative Studies in Education, 11(1), 7-24.

Lebeau, Y., \& Mills, D. (2008). From 'crisis' to 'transformation'? Shifting orthodoxies of African higher education policy and research. Learning and Teaching, 1(1), 58-88.

Luckett, K. M. (2006). The quality assurance of teaching and learning in higher education in South Africa: an analysis of national policy development and stakeholder response (Thesis). Stellenbosch: University of Stellenbosch. Retrieved from http://scholar.sun.ac.za/handle/10019.1/1127. Accessed 29 Apr 2009.

Maldonado-Torres, N. (2007). On the coloniality of being. Cultural Studies, 21(2-3), 240-270.

Mitchell, S. E. (1996). Institutions, individuals and talk: The construction of identity in fine art. International Journal of Art \& Design Education, 15(2), 143-154.

Moore, A. A. (1963). Why reparations? Reparations is the Battle cry for the economic and social freedom of more than 25 million descendants of American slaves. Los Angeles: Reparations Committee Incorporated.

O'Shea, S., Lysaght, P., Roberts, J., \& Harwood, V. (2016). Shifting the blame in higher education-Social inclusion and deficit discourses. Higher Education Research and Development, 35(2), 322-336.

Osorio, R. G. (2009). Class, race and access to higher education in Brazil (Classe, raça e acesso ao ensino superior no Brasil). Cadernos de Pesquisa, 39(138), 867-880 Cadernos de Pesquisa.

Paasche, K. I. M. (2006). An analysis of South Africa's education policy documents: Self-definition and definition of the 'other'. Lewiston: E. Mellen Press.

Pilkington, A. (2018). The rise and fall of the salience of race equality in higher education. In J. Arday \& H. S. Mirza (Eds.), Dismantling race in higher education. New York: Springer Berlin Heidelberg. https://www. palgrave.com/gb/book/9783319602608. Accessed 5 Dec 2018.

Republic of South Africa. (1998). Employment Equity Act No 55. Government Gazette 400 No. 19370. Cape Town.

Ryan, C. S., Hunt, J. S., Weible, J. A., Peterson, C. R., \& Casas, J. F. (2007). Multicultural and colorblind ideology, stereotypes, and ethnocentrism among black and white Americans. Group Processes \& Intergroup Relations, 10(4), 617-637.

Said, E. W. (1993). Culture and Imperialism. London: Chatto \& Windus.

Singh, M. (2011). The place of social justice in higher education and social change discourses. Compare: A Journal of Comparative and International Education, 41(4), 481-494. 
Smith, W. A., Mustaffa, J. B., Jones, C. M., Curry, T. J., \& Allen, W. R. (2016). 'You make me wanna holler and throw up both my hands!': Campus culture, Black misandric microaggressions, and racial battle fatigue. International Journal of Qualitative Studies in Education, 29(9), 1189-1209.

Soudien, C., Micheals, W., Mthembi-Mahanyele, S., Nkomo, M., Nyanda, G., Seepe, S., et al. (2008). Report of the ministerial committee on transformation and social cohesion and the elimination of discrimination in public higher education institutions: Final report. Pretoria: Department of Education http://www.voced.edu. $\mathrm{au} /$ content/ngv\%3A61442. Accessed 7 Aug 2017.

Stanley, C. A. (2006). Coloring the academic landscape: Faculty of color breaking the silence in predominantly white colleges and universities. American Educational Research Journal, 43(4), 701-736.

Stein, S., \& de Andreotti, V. O. (2016). Decolonization and higher education. In M. A. Peters (Ed.), Encyclopedia of educational philosophy and theory (pp. 1-6). Singapore: Springer Singapore.

Stronach, I., \& Piper, H. (Eds.). (2004). Educational research: Difference and diversity. Burlington: Ashgate.

Sulé, V. T. (2014). Enact, discard, and transform: A critical race feminist perspective on professional socialization among tenured Black female faculty. International Journal of Qualitative Studies in Education, 27(4), 432-453.

Tate, S. A., \& Bagguley, P. (2017). Building the anti-racist university: Next steps. Race Ethnicity and Education, 20(3), 289-299.

Thondhlana, G., \& Belluigi, D. Z. (2016). Students' reception of peer assessment of group-work contributions: Problematics in terms of race and gender emerging from a South African case study. Assessment in Higher Education, 42(7), 1118-1131.

Transformation Strategy Group. (2017). Transformation barometer framework. Universities South Africa. http:/www.usaf.ac.za/transformation-strategy-group/. Accessed 7 March 2018.

Transformation Strategy Group and Transformation Management Group. (2015). A transformation barometer for South African higher education. Pretoria: Universities South Africa.

Universities South Africa. (2015). ANNEXURE 5: Reflections on higher education transformation. In Transforming higher education for a transformed South Africa in a 21 century world: Call to action (pp. 1-24). Presented at the 2nd National Higher Education Transformation Summit, 2015, Durban: Universities South Africa. http://www.justice.gov.za/commissions/FeesHET/docs/2015-HESummit-Annexure05.pdf. Accessed 3 Apr 2016.

Venter, R. (2015). Transformation, theology and the public university in South Africa. Acta Theologica, 35(2), 173-203.

Verkuyten, M. (2006). Multicultural recognition and ethnic minority rights: A social identity perspective. European Review of Social Psychology, 17(1), 148-184.

Walker, M. (2005). Rainbow nation or new racism? Theorizing race and identity formation in South African higher education. Race Ethnicity and Education, 8(2), 129-146.

Wozolek, B. (2015). Are we not fatigued?: Queer battle fatigue at the intersection of heteronormative culture. Journal of Curriculum and Social Justice, 1(1), 186-214.

Publisher's note Springer Nature remains neutral with regard to jurisdictional claims in published maps and institutional affiliations. 